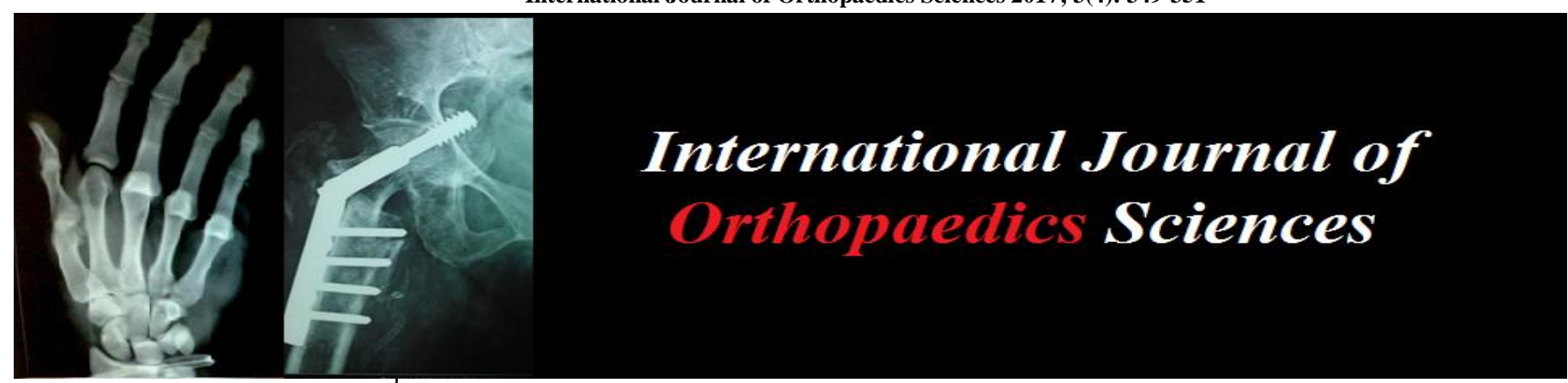

ISSN: $2395-1958$

IJOS 2017; 3(4): 349-351

(C) 2017 IJOS

www.orthopaper.com

Received: 19-08-2017

Accepted: 22-09-2017

\section{Rajni Ranjan}

Associate Professor, School of Medical Sciences \& Research, Knowledge Park-3, Greater Noida, Uttar Pradesh, India

\section{Rakesh Kumar}

Assistant Professor, School of Medical Sciences \& Research, L601, Amrapali Zodiac, Noida,

Utter Pradesh, India

Ajeet Singh

Consultant Orthopaedic Surgeon, R.K. Lifeline, Sirsa, Haryane, Sangwan Chowk, Sirsa,

Haryana, India
Correspondence Rajni Ranjan

Associate Professor, School of Medical Sciences \& Research, Knowledge Park-3, Greater Noida, Uttar Pradesh, India

\section{Original Research Article}

\section{Functional outcome of patients treated with proximal femoral nail for unstable trochanteric fractures}

\author{
Rajni Ranjan, Rakesh Kumar and Ajeet Singh
}

DOI: https://doi.org/10.22271/ortho.2017.v3.i4e.48

\section{Abstract}

Introduction: Proximal Femoral Nail has become a popular method of stabilization of unstable trochanteric fracture in adults. The aim of our study was to assess functional outcome, radiological result and complications in patient treated with Proximal Femoral Nail in unstable trochanteric fracture.

Material\& Method: 30 patients were treated with PFN for unstable trochanteric of femur. Patients were selected on the basis of inclusion and exclusion criteria. Final outcome assessment included fracture union, implant cutout, $\mathrm{Z}$ effect, reverse $\mathrm{Z}$ effect, loss of reduction in varus, nonunion, broken locking screw/PFN and Modified Harris Hip Score.

Result: This study included 25 male and 5 female above 18 years of age Major cause of injury was Road Traffic accident followed by fall at home. Modified Harris hip score was excellent in 19 patient, good in 7 patient fair in 3 and poor in 1 patient.

Conclusion: Proximal Femoral Nail is effective device in the treatment of unstable trochanteric fractures.

Keywords: proximal femoral nail, unstable trochanteric fracture, z effect, nonunion

\section{Introduction}

Fracture involving trochanteric region are common in elderly patient ${ }^{[1,2,3]}$. Incidence of the fracture has increased because the general life expectancy has increased significantly during last few decades ${ }^{[2,4]}$. Stable fixation and early mobilization decreases morbidity as well as mortality rates and improve functional results when trochanteric fracture is to be treated in geriatric patients ${ }^{[5]}$. Sliding hip screw in unstable trochanteric fracture are associated with significant complications in terms of medial displacement of the shaft and screw cut out ${ }^{[6]}$. Cephalomedullary nails has become a popular method of stabilization of unstable trochanteric fracture in adults. The aim of our study was to assess functional outcome, radiological result and complications in patient treated with Proximal Femoral Nail in unstable trochanteric fracture.

\section{Material \& Method}

Between January 2011 to December 2015, 30 patients were treated with PFN for unstable trochanteric fractures of the proximal femur. Patients were selected on inclusion and exclusion criteria.

Inclusion Criteria

1. Unstable trochanteric fracture.

Exclusion Criteria

2. Non ambulatory patient prior to injury

3. Severe neurological problems

4. Pathological Fracture (excluding osteoporosis)

5. Preexisting femoral deformity

Unstable trochanteric fracture pattern include 1. Reverse oblique fracture. 2. trochanteric with subtrochanteric extension 3. Large posteromedial fragment ${ }^{[7]}$ Surgery was performed under 
spinal anesthesia using fluoroscopy guided closed reduction on traction table. When closed reduction was unacceptable, limited open reduction was performed using various instrument as necessary. Distal locking done in all patients by free hand technique except in two where we have used short Proximal Femoral Nail and distal locking was done with help of targeting device. All patients were made to bear weight partially according to their pain tolerance level. Fracture union was determined radio graphically as the appearance of bridging callus on three or four cortices on AP and lateral view. Modified Harris Hip score was used to asses functional outcome. Late complications including implant cutout, $\mathrm{Z}$ effect, reverse $\mathrm{Z}$ effect, loss of reduction in varus, nonunion, broken locking screw, diaphyseal femoral fracture were considered during radiological assessment.

\section{Result}

This study included 25 male and 5 female above 18 years of age. All case operated in hospital within 7 days of injury. Major cause of injury was Road Traffic accident $(n=20)$ followed by fall at home $(n=8)$. Maximum no of patient were in age range above 60 . The mean time from hip fracture to osteosynthesis was with PFN was 4.5 day. There was no intra operative complication. Mean operative time was 71 minutes. Mean time of union was 16.2 weeks. Z Effect was seen in 2 patient. Both of them led to protrusion of hip pin through the femoral head, and were managed with implant removal. No reverse $\mathrm{Z}$ effect was seen. One patient developed non-union, which was treated by bone grafting. Persistent deep infection found in one patient which was initially treated by exploration of wound and IV antibiotic, fracture united in same patient in 36 weeks with discharging sinus. Implant was removed in this patient after one year of surgery, subsequently sinus healed. Varus malunion not seen in any patient. Implant failure in term of screw or nail breakage was not seen in any patient. Knee stiffness seen in 3 patients. Modified Harris hip score was excellent in 19 patients, good in 7 patients, fair in 3 patients and poor in 1 patient

\section{Discussion}

Hip fractures are a serious cause of concern in osteoporotic elderly population. The associated morbidity and mortality with hip fracture is significant ${ }^{[8]}$. The general consensus in the literature is that primary goal of treatment should be to obtain a stable fixation of the fracture that will allow early mobilization, restoring the function of limb [9] Current evidence support use of sliding hip screw for fixing the stable trochanteric fractures ${ }^{[7]}$. Historically, to provide satisfactory outcome in unstable trochanteric fractures, various implant have been developed ranging from extramedullary to intramedullary implant. Intramedullary implant like Proximal Femoral Nail have theoretical advantages like more efficient loading because of their location and less tensile strain on implant due to short lever arm and the consequent decrease in implant failure. It also allows controlled fracture impaction [10]. It allows early post-operative ambulation with a bio mechanically stable construct. Major cause of poor outcome are inadequate fracture reduction and use of inappropriate screw size ${ }^{[11]}$. Proximal Femoral Nail is technically demanding procedure, if careful attention given to minute technical details at each step, good outcome can be achieved. It is mandatory to achieve a good reduction between two main fragment without varus malalignment before making portal and insertion of nail. Other important requisite is to place screws in correct position ${ }^{[3,12]}$.

\section{Conclusion}

Proximal Femoral Nail is effective device in the treatment unstable trochanteric fractures. Although procedure is technically demanding, if surgeon gives careful attention to minute details at each step, good outcome is expected.

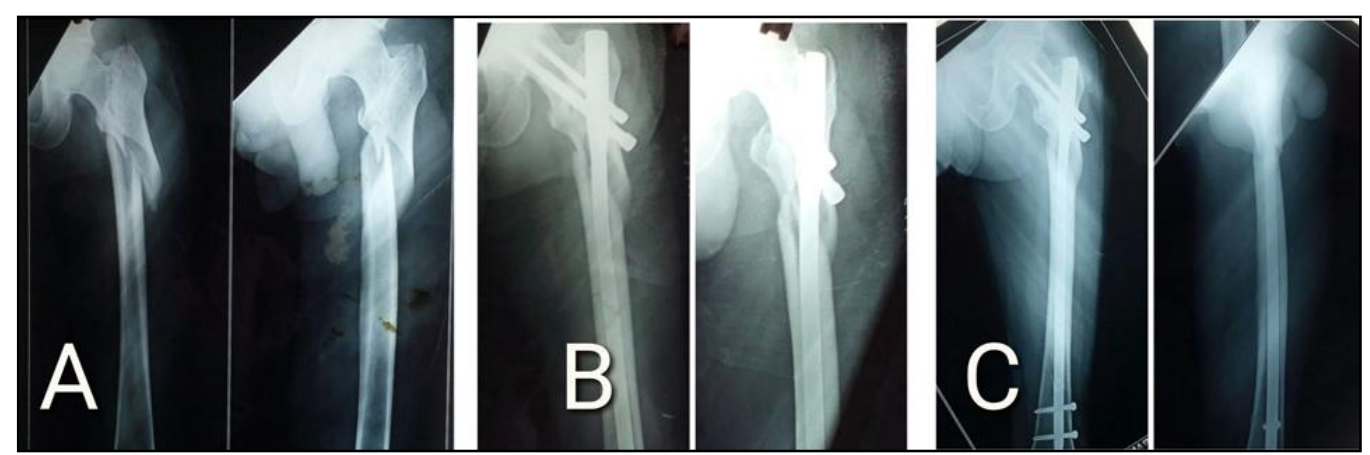

Fig 1: (A) Preoperative X Ray, (B) Postoperative X Ray, (C) Final Follow up X ray 


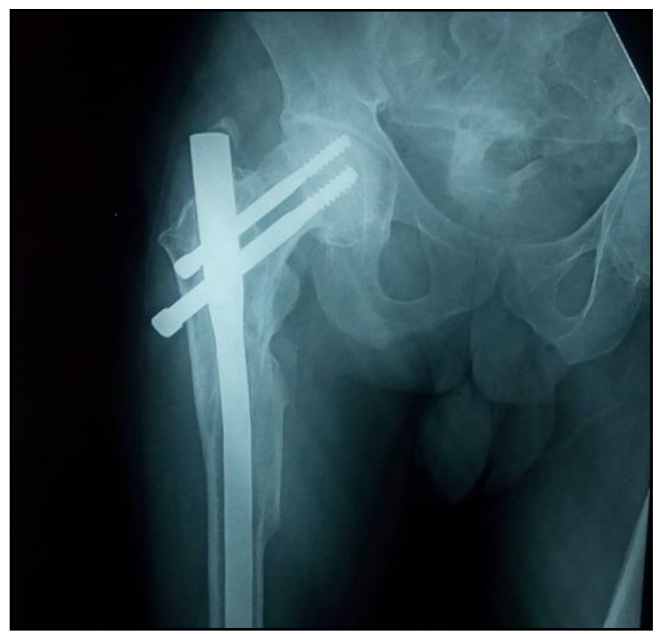

Fig 2: Z Effect

Table 1: Complications

\begin{tabular}{|c|c|c|}
\hline & No & Percentage \\
\hline Z effect & 2 & $6.7 \%$ \\
\hline Non union & 1 & $3.3 \%$ \\
\hline Varus collapse & 0 & $0 \%$ \\
\hline Knee stiffness & 3 & $10 \%$ \\
\hline Infection & 1 & $3.3 \%$ \\
\hline Implant failure & 0 & $0 \%$ \\
\hline
\end{tabular}

Table 2: Age distribution

\begin{tabular}{|c|c|c|}
\hline & No & Percentage \\
\hline $18-30$ & 6 & $20 \%$ \\
\hline $31-40$ & 7 & $23.3 \%$ \\
\hline $41-50$ & 5 & $16.7 \%$ \\
\hline $51-60$ & 4 & $13.3 \%$ \\
\hline$>60$ & 8 & $26.7 \%$ \\
\hline
\end{tabular}

Table 3: Mode of injury

\begin{tabular}{|c|c|c|}
\hline & No & Percentage \\
\hline Road traffic accident & 20 & $66.7 \%$ \\
\hline Fall at home & 8 & $26.67 \%$ \\
\hline Fall from Height & 1 & $3.3 \%$ \\
\hline Assault & 1 & $3.3 \%$ \\
\hline
\end{tabular}

Table 4: Modified Harris hip score

\begin{tabular}{|c|c|c|}
\hline Grade & No & Percentage \\
\hline Excellent & 19 & $63.3 \%$ \\
\hline Good & 7 & $23.3 \%$ \\
\hline Fair & 3 & $10 \%$ \\
\hline poor & 1 & $3.3 \%$ \\
\hline
\end{tabular}

\section{References}

1. Tyllianakis M, Panagopoulos A, Papasimos S, Mousafiris K. Treatment of extracapsular hip fractures with the proximal femoral nail (PFN): Long term results in 45 patients. Acta Orthop. Belg. 2004, 70.

2. Liu JJ, et al. Reason and treatment of failure of proximal femoral nail antirotation internal fixation for femoral intertrochanteric fractures of senile patients. Genetics and Molecular Research. 13(3):5

3. J Aithala P, Rao S. Proximal Femoral Nailing: Technical Difficulties and Results in Trochanteric Fractures. Open Journal of Orthopedics. 2013; 3(5).

4. Sadic, et al. Proximal Femoral Nail Antirotation in Treatment of Fractures of Proximal Femur Med Arch. 2014; 68(3).

5. Uzer G, Elmadağ NM, Yildız F, Bilsel K, Erden T, Toprak H. Comparison of two types of proximal femoral hails in the treatment of intertrochanteric femur fractures. Turkish Journal of Trauma and Emergency Sugery. 2015; 21(5).

6. Koyuncu S, Altay T, Kayalı C, Ozan F, Yamak K. Mechanical failures after fixation with proximal femoral nail and risk factors, Clinical Interventions in Aging. 2015; 10.

7. Mittal R, Banerjee S. Proximal femoral fractures: Principles of management and review of literature, J Clin Orthop Trauma. 2012; 3(1).

8. Sadic S, Custovic S, Jasarevuc M, Fazlic M, Krupic F. Proximal Femoral Nail Antirotation in Treatment of Intertrochanteric Hip Fractures: a Retrospective Study in 113 Patients. Med Arh. 2015; 69(6).

9. Raval P, Ramasamy A, Raza H, FEBOT, Khan K, Awan N. Comparison of Short vs Long Anti-rotation in Treating Trochanteric Fractures. Malaysian Orthopaedic Journal. 2016; 10(1).

10. Cheema GS, et al. Comparison of cutout resistance of dynamic condylar screw and proximal femoral nail in reverse oblique trochanteric fractures: A biomechanical study, Indian Journal of Orthopaedics. 2012; 46(3).

11. Koyuncu S, Altay T, Kayalı C, Ozan F, Yamak K. Mechanical failures after fixation with proximal femoral nail and risk factors, Clinical Interventions in Aging. $2015 ; 10$.

12. Morihara T, et al. Proximal femoral nail for treatment of trochanteric femoral fractures. Journal of Orthopaedic Surgery. 2007; 15(3). 